\title{
Factors Prognostic for Survival in Japanese Patients Treated with Sunitinib as First-line Therapy for Metastatic Clear Cell Renal Cell Cancer
}

\author{
Y Kawai ${ }^{1}$, T Osawa ${ }^{2}$, K Kobayashi ${ }^{1}$, R Inoue ${ }^{1}$, Y Yamamoto ${ }^{1}$, H Matsumoto ${ }^{1}$,

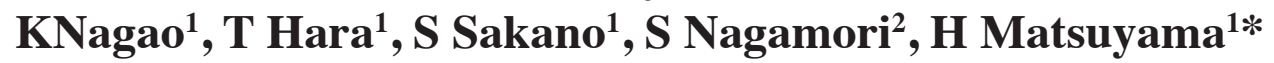

\begin{abstract}
Background: Factors predictive of survival have been identified in Western patients with metastatic clear cell renal cell carcinoma (mCCRCC) treated with sunitinib. Less is known, however, about factors predictive of survival in Japanese patients. This study evaluated factors prognostic of survival in Japanese patients with mCCRCC treated with first-line sunitinib. Materials and Methods: This retrospective study evaluated 46 consecutive Japanese mCCRCC patients treated with sunitinib as first line therapy. Clinical and biochemical markers associated with progression-free survival (PFS) were analyzed, with prognostic factors selected by uniand multivariate Cox regression analyses. Results: Univariate analysis showed that factors significantly associated with poor PFS included Memorial Sloan-Kettering Cancer Center poor risk scores, International Metastatic RCC Database Consortium poor risk and high $(>0.5 \mathrm{mg} / \mathrm{dl})$ serum C-reactive protein (CRP) concentrations (p<0.001 each). Multivariate analysis showed that high serum CRP was independently associated with poorer PFS ( $p=0.040)$. Six month disease control rate (complete response, partial response and stable disease) in response to sunitinib was significantly higher in patients with normal $(\leq 0.5 \mathrm{mg} / \mathrm{dl})$ than elevated baseline $\mathrm{CRP}(\mathrm{p}<0.001)$. Conclusions: CRP is a significant independent predictor of PFS for Japanese patients with mCCRCC treated with first-line sunitinib. Pretreatment CRP concentration may be a useful biomarker predicting response to sunitinib treatment.
\end{abstract}

Keywords: Metastatic renal cell carcinoma - sunitinib - prognosis

Asian Pac J Cancer Prev, 16 (14), 5687-5690

\section{Introduction}

Since the introduction of sunitinib (Sutent; Pfizer, New York, NY, USA) for patients with advanced renal cell carcinoma (RCC) (Motzer et al., 2006a), high objective response rates have been reported in western (47\%) (Motzer et al., 2006b; Motzer et al., 2009) and Japanese (52.9\%) (Tomita et al., 2010; Uemura et al., 2010) patients. Sunitinib has been approved worldwide for first-line treatment of metastatic clear-cell RCC (mCCRCC). However, not all patients respond to treatment (Rini and Atkins, 2009), and some may benefit more from other novel therapeutic strategies. To optimize and individualize treatment of patients with mCCRCC, prognostic markers are needed to select patients who would benefit most from sunitinib treatment. Although several predictive factors have been identified in western populations (Rini et al., 2011; Schmidinger et al., 2011; Fujita et al., 2012; Kawashima et al., 2012; Dirican et al., 2013; Gunduz et al., 2014), none of these models has been tested in native Japanese patients with mCCRCC treated with first-line sunitinib. This study was therefore designed to investigate the clinicopathological factors prognostic for progressionfree survival (PFS) in Japanese patients with mCCRCC treated with first-line sunitinib at two institutions.

\section{Materials and Methods}

The cohort consisted of 46 native Japanese patients with advanced clear cell RCC (CCRCC) who were treated with sunitinib as first-line therapy between November 2008 and July 2013 in two institution (University Hospital of Yamaguchi, Ube, Japan; and Hokkaido Cancer Center Hospital, Sapporo, Japan) (Table 1). The subjects included 37 males and 9 females, of median age 63 years at the time of sunitinib initiation. In general, patients were treated with $50 \mathrm{mg}$ /day oral sunitinib for 4 weeks, followed by 2 weeks without treatment, during each 6 week cycle. Written informed consent was obtained from all individuals enrolled in this study, which was approved by the institutional ethics committees of the Graduate School of Medicine, Yamaguchi University and Hokkaido Cancer Center.

Response and progression were assessed by the 


\section{Kawai et al}

treating physician based on RECIST version 1.0, with computed tomography (CT) or magnetic resonance imaging (MRI) performed every 6-8 weeks. Non-tumor variables were selected from among pretreatment characteristics, including patient age, sex, and Eastern Cooperative Oncology Group (ECOG) performance score (PS); sequence of sunitinib therapy; Memorial SloanKettering Cancer Center (MSKCC) risk score (Motzer et al., 2004); International Metastatic RCC Database Consortium (IMDC) risk classification (Heng et al., 2009); hemoglobin, serum C-reactive protein (CRP), serum lactate dehydrogenase (LDH), and corrected serum calcium concentrations; and neutrophil and platelet counts.

The primary endpoint was PFS, defined as the time from the date of initiation of sunitinib treatment to date of disease progression or last follow-up. A Cox regression model was used to calculate hazard ratios (HRs) for univariate and multivariate analyses. Factors prognostic of PFS were determined by Cox regression analysis using a step-wise forward selection, with $\mathrm{P}<0.05$ as the criterion for model entry or retention in multivariate analysis. Data were processed using JMP (version 11) software (SAS Institute, Cary, NC, USA).

\section{Table 1. Patient Characteristics}

\begin{tabular}{llr}
\hline Characteristic & & \\
\hline Median age, y (range) & Male & $63(39-83)$ \\
Sex $(\%)$ & Female & $37(64.2)$ \\
ECOG PS $(\%)$ & $<1$ & $9(35.8)$ \\
No. metastatic sites $(\%)$ & $>1$ & $37(88.7)$ \\
& 1 & $9(11.3)$ \\
Prior immunotherapy $(\%)$ & 2 & $11(35.8)$ \\
Prior nephrectomy $(\%)$ & $>2$ & $12(32.1)$ \\
& Yes & $23(32.1)$ \\
MSKCC risk classification $(\%)$ & No & $15(6.6)$ \\
& Yes & $31(43.4)$ \\
IMDC risk classification $(\%)$ & No & $28(75.5)$ \\
& Intermediate & $29(66.0)$ \\
& Poor & $15(17.0)$ \\
& Intermediate & $26(66.0)$ \\
& Poor & $18(17.0)$ \\
\hline
\end{tabular}

\section{Results}

The median follow-up period from the initiation of sunitinib treatment was 21.2 months. The median PFS and OS for the total study population were 9.6 and 18.1 months, respectively.

Univariate analysis of the impact of several clinical factors on PFS showed that MSKCC and IMDC poor risk scores, and high ( $>0.5 \mathrm{mg} / \mathrm{dl}) \mathrm{CRP}$ concentration were associated with poorer PFS (Table 2). In contrast, patient age, gender, ECOG PS, hemoglobin concentration, serum LDH concentration, corrected serum calcium concentration, neutrophil count and platelet count were not prognostic of PFS. Multivariate analysis showed that only normal $(\leq 0.5 \mathrm{mg} / \mathrm{dl}) \mathrm{CRP}$ concentration was independently prognostic of improved PFS. Kaplan-Meier

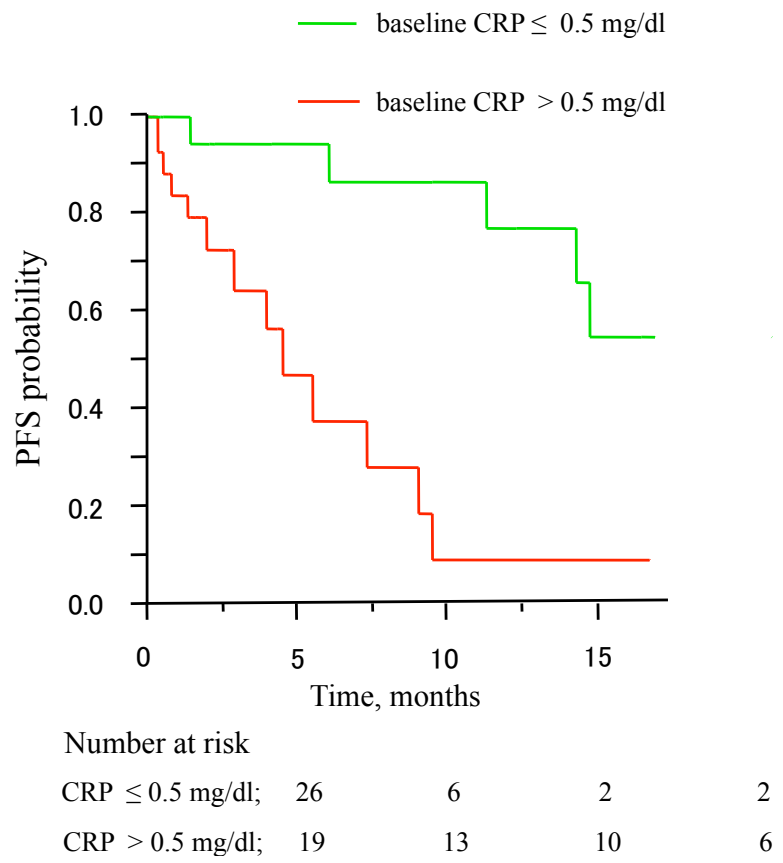

Figure 1. Kaplan-Meier Analysis of Progression-free Survival (PFS) in Patients with Normal $(\leq 0.5 \mathrm{mg} / \mathrm{dL})$ and Elevated $(>0.5 \mathrm{mg} / \mathrm{dL}) \mathrm{C}$-reactive Protein (CRP) Concentrations. Median PFS was significantly higher for patients with normal than elevated CRP (24.2 vs. 4.6 months; log-rank $\mathrm{p}<0.001)$

Table 2. Univariate and Multivariate Analysis of Baseline Factors Prognostic for Progression-free Survival

\begin{tabular}{|c|c|c|c|c|}
\hline Variable & Univariate analysis Risk ratios (95\% CI) & P-value & Multivariate analysis Risk ratios (95\% CI) & P-value \\
\hline Age (> 63 yrs) & $1.16(0.71-1.85)$ & 0.54 & & \\
\hline Sex (female) & $1.14(0.64-1.87)$ & 0.62 & & \\
\hline ECOG PS $(>1)$ & $3.24(0.85-10.30)$ & 0.079 & & \\
\hline Prior immunotherapy (+) & $0.64(0.24-1.63)$ & 0.36 & & \\
\hline Prior nephrectomy $(+)$ & $0.48(0.19-1.24)$ & 0.13 & & \\
\hline MSKCC (poor risk) & $2.74(1.54-5.10)$ & $<0.001$ & $1.34(0.65-3.17)$ & 0.45 \\
\hline IMDC (poor risk) & $2.24(1.39-3.70)$ & $<0.001$ & $1.62(0.75-3.14)$ & 0.21 \\
\hline $\mathrm{Hb}(<\mathrm{LLN})$ & $2.09(0.76-5.40)$ & 0.12 & & \\
\hline $\mathrm{LDH}(\geq 1.5 \mathrm{ULN})$ & $1.84(0.94-3.72)$ & 0.075 & & \\
\hline Corrected Ca $(\geq 10 \mathrm{mg} / \mathrm{dl})$ & $1.32(0.52-3.30)$ & 0.55 & & \\
\hline Neutrophil count ( $\geq$ ULN) & $1.96(0.69-6.37)$ & 0.21 & & \\
\hline Plt $(\geq$ ULN) & $1.35(0.07-8.41)$ & 0.79 & & \\
\hline $\mathrm{CRP}(\geq 0.5 \mathrm{mg} / \mathrm{dl})$ & $2.43(1.44-4.41)$ & $<0.001$ & $1.99(1.03-3.89)$ & 0.040 \\
\hline
\end{tabular}

*Abbreviations: ECOG, Eastern Cooperative Oncology Group; MSKCC, Memorial Sloan-Kettering Cancer Center; IMDC, International Metastatic RCC Database Consortium; LLN, lower limit of normal; ULN, upper limit of normal; Hb, hemoglobin; Plt, platelets; CRP, C-reactive protein 
Response Rate

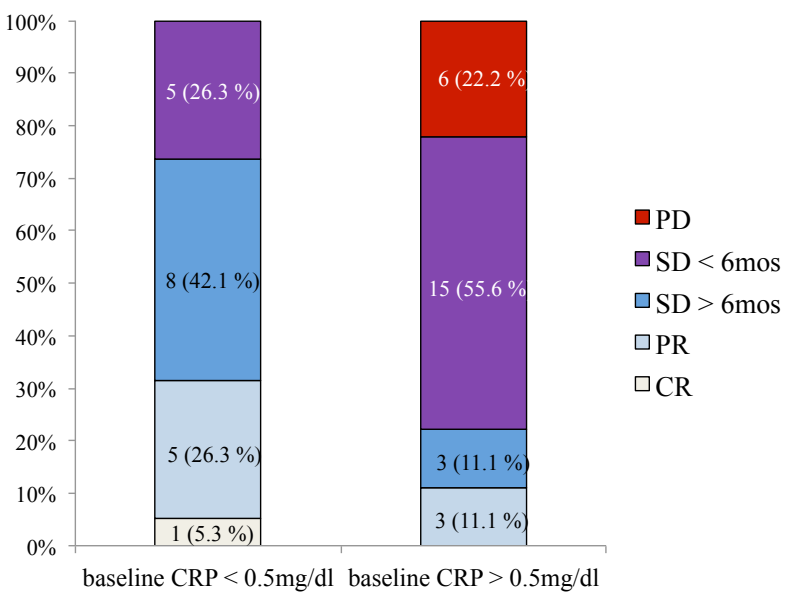

Figure 2. Overall Response Rate (ORR) as Function of Baseline C-reactive Protein (CRP) Concentration Levels. ORR was significantly higher in patients with normal $(\leq 0.5 \mathrm{mg} / \mathrm{dl})$ than elevated $(>0.5 \mathrm{mg} / \mathrm{dl}) \mathrm{CRP}(31.6 \%$ vs. $11.1 \% ; \mathrm{p}<0.001)$

analysis showed that median PFS was significantly higher for patients with normal than elevated CRP (24.2 vs 4.6 months, $\mathrm{p}<0.001$; Figure 1).

Of the 46 patients treated with sunitinib, $1(2.2 \%)$ achieved a complete response (CR), 8 (17.4\%) achieved partial response (PR), 11 (23.9\%) had stable disease (SD) for at least 6 months, $20(43.5 \%)$ had SD for less than 6 months, and $6(13.0 \%)$ had progressive disease (PD). Thus, the objective response rate (ORR) was $19.6 \%$ and the disease control rate (DCR) was $43.5 \%$. In the group with normal $(\leq 0.5 \mathrm{mg} / \mathrm{dl})$ baseline CRP, $73.7 \%$ of patients experienced a CR, or PR or SD at least for 6 months compared with $22.2 \%$ of patients in the group with elevated $(>0.5 \mathrm{mg} / \mathrm{dl})$ baseline CRP $(\mathrm{p}<0.001)$ (Figure 2$)$. Interestingly, none of the patients with normal baseline CRP experienced PD.

\section{Discussion}

Sunitinib was the first tyrosine kinase inhibitor (TKI) approved for the treatment of patients with $\mathrm{mRCC}$ (Motzer et al., 2009). However, some of these patients may not benefit from sunitinib treatment, and sunitinib has several severe adverse effects (Motzer et al., 2009; Rini and Atkins, 2009). Pre-treatment biomarkers are useful in assessing the efficacy of therapeutic interventions, as well as in counseling patients, individualizing follow-up, choosing treatment options, selecting patients for clinical trials and predicting prognosis.

We found that pretreatment CRP concentration was an independent prognostic factor in mCCRCC patients treated with sunitinib. Our findings suggest that patients with high $(>0.5 \mathrm{mg} / \mathrm{dl})$ serum CRP levels may not benefit from sunitinib therapy. Several previous studies have reported that CRP concentration is significantly prognostic of metastasis and mortality in RCC patients (Dai et al., 2014), including Japanese patients (Karakiewicz et al., 2007; Naito et al., 2010). Furthermore, CRP was reported to be a predictive marker in RCC patients treated with sunitinib RCC (Fujita et al., 2012; Beuselinck et al., 2013; Miyake et al., 2014). To our knowledge, however none of these earlier studies reported that CRP was independently prognostic of PFS in native Japanese mCCRCC patients treated with first-line sunitinib.

Elevated CRP identifies tumors capable of producing significant amounts of pro-inflammatory cytokines, in particular interleukin (IL)-6 (Kinoshita et al., 1999; McKeown et al., 2004). Cells in these tumors have the potential for more rapid growth (Jee et al., 2001; Trikha et al., 2003). Moreover, a systemic inflammatory response and its associated nutritional decline (McMillan et al., 1998; Scott et al., 2002) may affect how patients tolerate and comply with active treatment (Bromwich et al., 2004; Forrest et al., 2004).

The ORR in this patient cohort was $19.6 \%$, which was lower than in a western phase III trial $(30.7 \%)$ (Motzer et al., 2007) and a Japanese phase II trial (47.6\%) (Uemura et al., 2010), although similar to the ORR of $17.4 \%$ reported in an international expanded-access trial of sunitinib (Gore et al., 2009). The baseline characteristics of the patients in this series seem to be unfavorable compared with those in previous clinical trials. For example, the proportion of patients categorized as poor risk according to MSKCC classification score was over 3-fold higher in this series than in the earlier phase III trial (Motzer et al., 2007). In this series, the median PFS and OS for the total study population were 9.6 and 18.1 months, respectively, comparable with those in a previous international trial (Gore et al., 2009).

The present study was limited by its retrospective design and small patient cohort, limiting the power of analyses. These drawbacks allowed us to draw only preliminary conclusions. Nevertheless, our findings suggest that CRP concentration has potential prognostic significance in patients with mCCRCC treated with sunitinib. Further investigations with large study cohorts are needed to validate our findings.

In conclusion, this study showed that CRP is a significant independent prognostic indicator for Japanese patients with mCCRCC treated with sunitinib as first-line targeted therapy. Pretreatment CRP concentration may be a useful biomarker of response to sunitinib treatment. Further studies are required to clarify the prognostic role of this biomarker, both in patients treated with sunitinib and those treated with other targeted agents.

\section{References}

Beuselinck B, Vano YA, Oudard S, et al (2014). Prognostic impact of baseline serum C-reactive protein in patients with metastatic renal cell carcinoma (RCC) treated with sunitinib. BJU Int, 114, 81-9.

Bromwich E, McMillan DC, Lamb GW, Vasey PA, Atchison M (2004). The systemic inflammatory response, performance status and survival in patients undergoing alpha-interferon treatment for advanced renal cancer. Br J Cancer, 91, 1236-8.

Dai J, Tang K, Xiao W, et al (2014). Prognostic significance of $\mathrm{C}$-reactive protein in urological cancers: a systematic review and meta-analysis. Asian Pac J Cancer Prev, 15, 3369-75.

Dirican A, Kucukzeybek Y, Erten C, et al (2013). Prognostic and predictive value of hematologic parameters in patients 
with metastatic renal cell carcinoma: second line sunitinib treatment following IFN-alpha. Asian Pac J Cancer Prev, 14, 2101-5.

Forrest LM, McMillan DC, McArdle CS, Angerson WJ, Dunlop DJ (2004). Comparison of an inflammation-based prognostic score (GPS) with performance status (ECOG) in patients receiving platinum-based chemotherapy for inoperable nonsmall-cell lung cancer. Br J Cancer, 90, 1704-6.

Fujita T, Iwamura M, Ishii D, et al (2012). C-reactive protein as a prognostic marker for advanced renal cell carcinoma treated with sunitinib. Int J Urol, 19, 908-13.

Gore ME, Szczylik C, Porta C, et al (2009). Safety and efficacy of sunitinib for metastatic renal-cell carcinoma: an expandedaccess trial. Lancet Oncol, 10, 757-63.

Gunduz S, Mutlu H, Uysal M, Coskun HS, Bozcuk H (2014). Prognostic value of hematologic parameters in patients with metastatic renal cell carcinoma using tyrosine kinase inhibitors. Asian Pac J Cancer Prev, 15, 3801-4.

Heng DY, Xie W, Regan MM, et al (2009). Prognostic factors for overall survival in patients with metastatic renal cell carcinoma treated with vascular endothelial growth factortargeted agents: results from a large, multicenter study. $J$ Clin Oncol, 27, 5794-9.

Jee SH, Shen SC, Chiu HC, Tsai WL, Kuo ML (2001). Overexpression of interleukin-6 in human basal cell carcinoma cell lines increases anti-apoptotic activity and tumorigenic potency. Oncogene, 20, 198-208.

Karakiewicz PI, Hutterer GC, Trinh QD, et al (2007). C-reactive protein is an informative predictor of renal cell carcinomaspecific mortality: a European study of 313 patients. Cancer, 110, 1241-7.

Kawashima A, Tsujimura A, Takayama H, et al (2012). Impact of hyponatremia on survival of patients with metastatic renal cell carcinoma treated with molecular targeted therapy. Int $J$ Urol $, 19,1050-7$; author reply 1058-9.

Kinoshita T, Ito H, Miki C (1999). Serum interleukin-6 level reflects the tumor proliferative activity in patients with colorectal carcinoma. Cancer, 85, 2526-31.

McKeown DJ, Brown DJ, Kelly A, Wallace AM, McMillan DC (2004). The relationship between circulating concentrations of C-reactive protein, inflammatory cytokines and cytokine receptors in patients with non-small-cell lung cancer. $\mathrm{Br} J$ Cancer, 91, 1993-5.

McMillan DC, Scott HR, Watson WS, et al (1998). Longitudinal study of body cell mass depletion and the inflammatory response in cancer patients. Nutr Cancer, 31, 101-5.

Miyake H, Miyazaki A, Harada K, Fujisawa (2014). Assessment of efficacy, safety and quality of life of 110 patients treated with sunitinib as first-line therapy for metastatic renal cell carcinoma: experience in real-world clinical practice in Japan. Med Oncol, 31, 978.

Motzer RJ, Bacik J, Mazumdar M (2004). Prognostic factors for survival of patients with stage IV renal cell carcinoma: Memorial Sloan-Kettering Cancer Center experience. Clin Cancer Res, 10, 6302-3.

Motzer RJ, Hutson TE, Tomczak P, et al (2009). Overall survival and updated results for sunitinib compared with interferon alfa in patients with metastatic renal cell carcinoma. J Clin Oncol, 27, 3584-90.

Motzer RJ, Hutson TE, Tomczak P, et al (2007). Sunitinib versus interferon alfa in metastatic renal-cell carcinoma. $N$ Engl $J$ Med, 356, 115-24.

Motzer RJ, Michaelson MD, Redman BG, et al (2006a). Activity of SU11248, a multitargeted inhibitor of vascular endothelial growth factor receptor and platelet-derived growth factor receptor, in patients with metastatic renal cell carcinoma. $J$ Clin Oncol, 24, 16-24.
Motzer RJ, Rini BI, Bukowski RM, et al (2006b). Sunitinib in patients with metastatic renal cell carcinoma. JAMA, 295, 2516-24.

Naito S, Yamamoto N, Takayama T, et al (2010). Prognosis of Japanese metastatic renal cell carcinoma patients in the cytokine era: a cooperative group report of 1463 patients. Eur Urol, 57, 317-25.

Rini BI, Atkins MB (2009). Resistance to targeted therapy in renal-cell carcinoma. Lancet Oncol, 10, 992-1000.

Rini BI, Cohen DP, Lu DR, et al (2011). Hypertension as a biomarker of efficacy in patients with metastatic renal cell carcinoma treated with sunitinib. $J$ Natl Cancer Inst, 103, 763-73.

Schmidinger M, Vogl UM, Bojic M, et al (2011). Hypothyroidism in patients with renal cell carcinoma: blessing or curse? Cancer, 117, 534-44.

Scott HR, McMillan DC, Forrest LM, et al (2002). The systemic inflammatory response, weight loss, performance status and survival in patients with inoperable non-small cell lung cancer. Br J Cancer, 87, 264-7.

Tomita Y, Shinohara N, Yuasa T, et al (2010). Overall survival and updated results from a phase II study of sunitinib in Japanese patients with metastatic renal cell carcinoma. Jpn J Clin Oncol, 40, 1166-72.

Trikha M, Corringham R, Klein B, Rossi JF (2003). Targeted anti-interleukin-6 monoclonal antibody therapy for cancer: a review of the rationale and clinical evidence. Clin Cancer Res, 9, 4653-65.

Uemura H, Shinohara N, Yuasa T, et al (2010). A phase II study of sunitinib in Japanese patients with metastatic renal cell carcinoma: insights into the treatment, efficacy and safety. Jpn J Clin Oncol, 40, 194-202. 